\title{
PENGUJIAN PENGGUNAAN BIOCHAR BERBAHAN BAKU SISA POHON KELAPA SAWIT TERHADAP PERTUMBUHAN BIBIT KELAPA SAWIT (Elaeis guineensis Jacq.) DI MAIN NURSERY PADA TANAH ULTISOL ASAL GALANG
}

\author{
Jusy Siboro \\ Program Studi Agroteknologi \\ Fakultas Pertanian, Universitas Sumatera Utara, Medan 20155, Indonesia \\ jusysiboro123456@gmail.com
}

\begin{abstract}
The rest of the oil palm plantations in large quantities, if not processed, can damage the environment. if used properly, it can be used as biochar, which functions to improve the soil. This study aims to determine the effect of testing the use of Biochar made from raw residual Palm Oil Trees for The Growth Of Palm Oil Seeds (Elaeis guenensis Jacq.) in the Main Nursery in Ultisol. The research was conducted using a complete randomized design (RAL) non factorial with 4 replications. The factors is biochar consisting of 5 treatments: BO (Control); B1 (biochar of stem palm oil); B2 (biochar of palm oil fronds); B3 (biochar of empty fruit bunch compost); B4 (biochar of stem palm oil + fronds + oil empty fruit bunch compost). The parameters observed were plant height, diameter of the stem and number of leaves. The results showed that administration of biochar had no significant effect on increasing plant height, application of biochar also had no significant effect on increasing the diameter the stem, application of biochar had no significant effect on increasing the giving biochar had no number of leaves of oil palm seedlings.
\end{abstract}

\begin{abstract}
Abstrak
Sisa dari tanaman kelapa sawit dalam jumlah yang banyak, jika dibiarkan dapat merusak lingkungan. Apabila dimanfaatkan dengan baik dapat digunakan sebagai biochar yang berfungsi menjadi pembenah tanah. Penelitian ini bertujuan untuk mengetahui pengaruh Pengujian Penggunaan Biochar Berbahan Baku Sisa Pohon Kelapa Sawit untuk Pertumbuhan Bibit Kelapa Sawit (Elaeis guenensis Jacq.) Di Main Nursery pada Tanah Ultisol. Metode yang digunakan adalah rancangan acak lengkap non faktorial dan 4 ulangan. Faktornya yaitu biochar terdiri dari 5 perlakuan: B0 (Kontrol); B1 (biochar batang kelapa sawit); B2 (biochar pelepah kelapa sawit); B3( biochar tandan kosong kelapa sawit); B4 (biochar batang + pelepah + tandan kosong kelapa sawit). Parameter yang diamati adalah tinggi tanaman, diameter lilit batang, dan jumlah daun. Hasil penelitian menunjukkan bahwa pemberian biochar berpengaruh tidak nyata meningkatkan tinggi tanaman, biochar berpengaruh tidak nyata meningkatkan diameter lilit batang, biochar berpengaruh tidak nyata meningkatkan jumlah daun bibit kelapa sawit.
\end{abstract}

Kata kunci : Tanaman kelapa sawit, bibit kelapa sawit, biochar, tanah Ultisol

\section{Pendahuluan}

Kelapa sawit merupakan tanaman perkebunan yang menduduki posisi penting dalam sektor perkebunan. Luas perkebunan kelapa sawit Indonesia mencapai 11.67 juta hektar, dengan 
rincian luas areal perkebunan swasta 6.15 juta hektar, perkebunan rakyat 4.76 juta hektar dan perkebunan negara 756 ribu hektar (Direktorat jenderal perkebunan, 2016). Kelapa sawit merupakan komoditi andalan Indonesia yang perkembangannya sangat pesat. Tanaman kelapa sawit di perkebunan dapat tumbuh dengan baik pada kisaran suhu 24-28oC. Untuk memperoleh hasil maksimal dalam budidaya kelapa sawit perlu memperhatikan sifat fisik dan kimia tanah di pengolahan kelapa sawit baik berupa limbah padat maupun limbah cair (Haryanti et al., 2014).

Bibit kelapa sawit membutuhkan media tanam yang mempunyai sifat fisik dan kimia yang baik. Media tanam yang biasa digunakan dan pembibitan kelapa sawit adalah tanah lapisan atas (top soil) dengan ketebalan 10-20 cm dari permukaan tanah yang di campur dengan pasir dan bahan organik, sehingga diperoleh media dengan kesuburan yang baik. Sekarang ini ketersediaan top soil yang subur dan potensial semakin berkurang akibat tingginya pemanfaatan lahan untuk berbagai kepentingan (Armaini et al., 2013).

Biochar adalah produk kaya karbon yang diperoleh dari biomassa pertanian, seperti kayu yang dipanaskan dalam wadah tertutup dengan sedikit atau tanpa udara yang tersedia. Dalam istilah yang lebih teknis, biochar diproduksi oleh dekomposisi termal yang disebut bahan organik di bawah pasokan oksigen terbatas $(\mathrm{O} 2)$ dan pada suhu yang relatif rendah $(<700$ $\left.{ }^{\circ} \mathrm{C}\right)$ (Lehnmann and stephan, 2009).

Biochar berkontribusi terhadap pembenahan sifat fisika dan kimia tanah seperti retensi hara yaitu N, P, K, Ca, Mg, KTK dan retensi air tanah. Meningkatnya nilai KTK tanah dengan penambahan biochar akan meminimalkan resiko pencucian kation seperti $\mathrm{K}+$ dan $\mathrm{NH} 4+$. Biochar juga mempengaruhi peningkatan retensi air tanah akibat penambahan pembenahan organik ini mempunyai hubungan kuat dengan menurunnya jumlah pori makro tanah. Sifat biochar yang kaya dengan pori mikro jika diaplikasikan ke tanah berpasir yang secara tipikal mempunyai luas permukaan spesifik terbatas sehingga menyebabkan bertambahnya jumlah pori mikro tanah (Sukartono dan Utomo, 2010).

Ultisol mempunyai penampang tanah yang dalam sehingga merupakan media yang baik bagi pertumbuhan tanaman kecuali Ultisol yang mempunyai horizon kandik. Penampang tanah yang dalam dengan kapasitas tukar kation sedang hingga tinggi menjadikan tanah Ultisol dapat dimanfaatkan untuk berbagai jenis tanaman. Namun demikian, faktor iklim dan relief perlu diperhatikan. Kendala pemanfaatan tanah Ultisol untuk pengembangan pertanian adalah kemasaman dan kejenuhan Al yang tinggi, kandungan hara dan bahan organik rendah, serta tanah peka terhadap erosi. pemanfaatan tanah ini menghadapi kendala karakteristik tanah yang dapat menghambat pertumbuhan tanaman terutama tanaman pangan bila tidak dikelola dengan baik. Beberapa kendala yang umum pada tanah Ultisol adalah kemasaman tanah tinggi, $\mathrm{pH}$ rata-rata $<4,50$, kejenuhan Al tinggi, miskin kandungan hara makro terutama $\mathrm{P}, \mathrm{K}, \mathrm{Ca}, \mathrm{Mg}$, dan kandungan bahan organik rendah. Untuk mengatasi kendala tersebut dapat diterapkan teknologi pengapuran, pemupukan $\mathrm{P}$ dan $\mathrm{K}$, serta pemberian bahan organik. Penambahan biochar sebagai pembenah tanah yang berasal dari hasil pembakaran limbah produk pertanian dengan oksigen terbatas, ternyata memiliki potensi yang baik sebagai bahan pembenah tanah, karena $\mathrm{C}$ organik masih tetap bertahan di dalam karbon hitam (biochar). Pemanfaatan tanah Ultisol untuk pengembangan tanaman 
pangan maupun tanaman perkebunan sudah dapat teratasi dengan pemberian biochar untuk mendukung pertanian berkelanjutan (Sujana dan I Nyoman, 2015).

\section{Bahan dan Metode}

Penelitian ini dilaksanakan di rumah kaca fakultas pertanian universitas sumatera utara, medan pada tahun 2018.

Bahan yang digunakan dalam penelitian ini adalah bibit kelapa sawit DxP Yangambi, biochar dari pelepah kelapa sawit, batang kelapa sawit, dan tandan kosong kelapa sawit, dan tanah ultisol sebagai bahan tanam, air dan sejumlah bahan-bahan di laboratorium. Polybag sebagai wadah untuk kompos dan tanah, label yang digunakan untuk memberi tanda pada polybag.

Alat yang digunakan adalah cangkul digunakan untuk mengolah tanah dan membersihkan lahan penelitian, meteran untuk mengukur luas lahan, timbangan analitik untuk menimbang bahan pendukung penelitian, spidol/pensil sebagai alat tulis, kamera sebagai alat dokumentasi, gembor sebagai alat untuk menyiram. Label untuk penanda polybag dan gembor untuk menyiram tanaman.

Penelitian ini menggunakan Rancang Acak Lengkap (RAL) nonfaktorial dengan 5 perlakuan yaitu Kontrol (B0), Biochar Batang Kelapa Sawit (B1), Biochar Pelepah Kelapa Sawit (B2), Biochar Tandan Kosong Kelapa Sawit (B3) dan Kombinasi dari ketiga biochar (B4). Selanjutnya dilakukan 4 ulangan pada setiap perlakuan

Parameter yang diamati adalah tinggi tanaman, diameter lilit batang dan jumlah Pelepah.

\section{Hasil dan Pembahasan}

Hasil

\section{Tinggi Tanaman}

Dari data tinggi tanaman (Tabel 1), dan dari hasil sidik ragam diperoleh bahwa pemberian biochar berpengaruh tidak nyata dalam meningkatkan pertumbuhan tinggi tanaman bibit kelapa sawit di Main Nursery.

Tabel 1. Data rataan tinggi tanaman $(\mathrm{cm})$ akibat pemberian biochar selama1-12 MST.

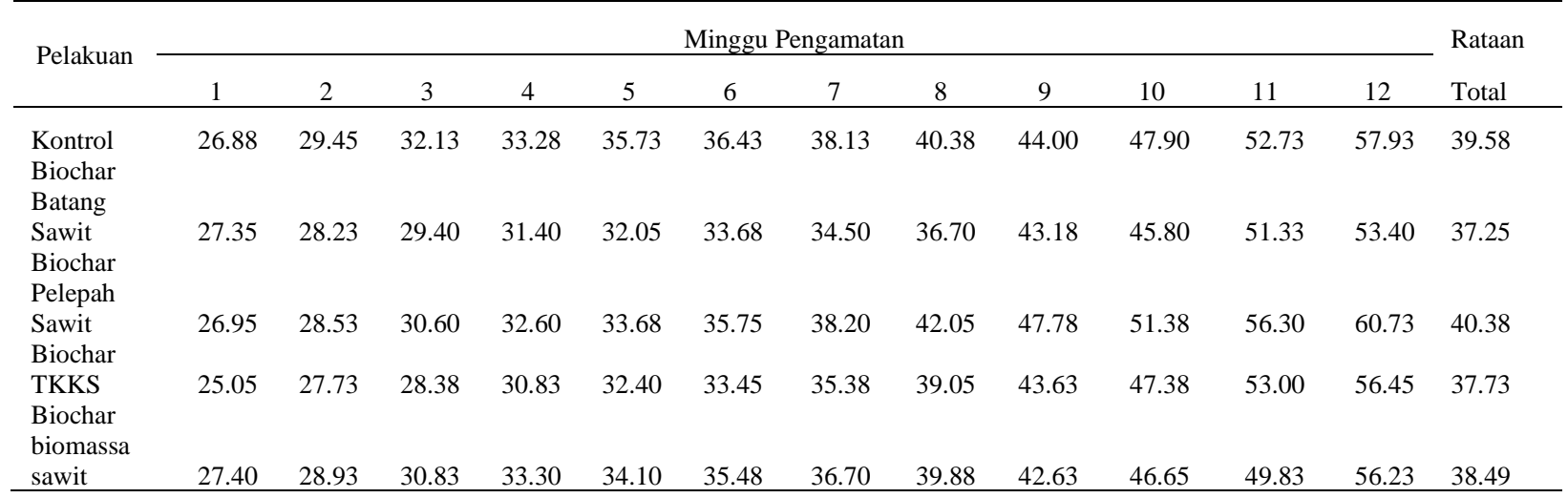




\section{Diameter Lilit Batang}

Dari data diameter lilit batang (Tabel 2), dan dari hasil sidik ragam diperoleh bahwa pemberian biochar berpengaruh tidak nyata dalam meningkatkan pertumbuhan diameter lilit batang bibit kelapa sawit di Main Nursery.

Tabel 2. Data rataan diameter lilit (mm) batang akibat pemberian biochar selama1-12 MST.

\begin{tabular}{|c|c|c|c|c|c|c|c|c|c|c|c|c|c|}
\hline \multirow{2}{*}{ Pelakuan } & \multicolumn{12}{|c|}{ Minggu Pengamatan } & \multirow{2}{*}{$\begin{array}{r}\text { Rataan } \\
\text { Total } \\
\end{array}$} \\
\hline & 1 & 2 & 3 & 4 & 5 & 6 & 7 & 8 & 9 & 10 & 11 & 12 & \\
\hline $\begin{array}{l}\text { Kontrol } \\
\text { Biochar }\end{array}$ & 6.38 & 7.15 & 8.20 & 9.08 & 10.55 & 12.10 & 13.88 & 14.83 & 15.55 & 16.20 & 17.83 & 18.33 & 12.50 \\
\hline $\begin{array}{l}\text { Batang } \\
\text { Sawit } \\
\text { Biochar } \\
\text { Pelepah }\end{array}$ & 8.10 & 8.63 & 9.33 & 10.10 & 11.13 & 12.53 & 13.70 & 15.00 & 16.40 & 17.88 & 19.28 & 21.50 & 13.63 \\
\hline $\begin{array}{l}\text { Sawit } \\
\text { Biochar }\end{array}$ & 7.30 & 7.50 & 8.23 & 9.53 & 10.25 & 12.18 & 14.05 & 15.15 & 16.28 & 17.33 & 18.70 & 20.50 & 13.08 \\
\hline $\begin{array}{l}\text { TKKS } \\
\text { Biochar } \\
\text { Biomassa }\end{array}$ & 7.88 & 8.45 & 9.50 & 10.28 & 11.45 & 13.05 & 13.25 & 15.83 & 16.98 & 17.83 & 19.05 & 21.08 & 13.72 \\
\hline Sawit & 7.15 & 7.43 & 8.28 & 9.18 & 11.13 & 12.13 & 13.23 & 14.48 & 16.50 & 17.55 & 18.95 & 20.93 & 13.08 \\
\hline
\end{tabular}

\section{Jumlah Pelepah}

Pemberian biochar dari beberapa jenis bahan baku tidak berpengaruh nyata dalam meningkatkan jumlah daun bibit kelapa sawit di Main Nursery pada tanah Ultisol (Tabel 3).

Tabel 3. Data Rataan Jumlah Pelepah(helai) Akibat Pemberian Biochar Selama 1-12 MST.

\begin{tabular}{|c|c|c|c|c|c|c|c|c|c|c|c|c|c|}
\hline \multirow{2}{*}{ Pelakuan } & \multicolumn{12}{|c|}{ Minggu Pengamatan } & \multirow{2}{*}{$\begin{array}{c}\text { Rataan } \\
\text { Total }\end{array}$} \\
\hline & 1 & 2 & 3 & 4 & 5 & 6 & 7 & 8 & 9 & 10 & 11 & 12 & \\
\hline $\begin{array}{l}\text { Kontrol } \\
\text { Biochar }\end{array}$ & 3.50 & 3.50 & 4.50 & 4.75 & 5.25 & 5.25 & 6.00 & 6.25 & 6.50 & 7.00 & 7.50 & 7.75 & 5.65 \\
\hline $\begin{array}{l}\text { Batang Sawit } \\
\text { Biochar } \\
\text { Pelepah }\end{array}$ & 4.25 & 4.50 & 4.75 & 5.25 & 5.50 & 6.25 & 6.50 & 6.75 & 7.00 & 7.75 & 8.00 & 8.75 & 6.27 \\
\hline $\begin{array}{l}\text { Sawit } \\
\text { Biochar }\end{array}$ & 4.00 & 4.00 & 4.75 & 4.75 & 5.50 & 5.50 & 6.25 & 6.75 & 6.75 & 7.50 & 8.00 & 8.25 & 6.00 \\
\hline $\begin{array}{l}\text { TKKS } \\
\text { Biochar }\end{array}$ & 4.25 & 4.50 & 5.00 & 5.50 & 6.00 & 6.00 & 6.75 & 7.00 & 7.25 & 7.75 & 8.25 & 8.50 & 6.40 \\
\hline Gabungan & 4.25 & 4.50 & 4.50 & 5.25 & 5.50 & 6.00 & 6.50 & 6.75 & 7.00 & 7.50 & 8.00 & 8.50 & 6.19 \\
\hline
\end{tabular}

Berdasarkan hasil penelitian pada Tabel 1, Tabel 2, dan Tabel 3 diperoleh bahwa pemberianbiochar berpengaruh tidak nyata terhadap tinggi tanaman (Tabel 1), diameter batang (Tabel 2) dan, jumlah pelepah (Tabel 3) kelapa sawit selama 12 minggu sesudah tanam. Hal ini menunjukkan bahwa fungsi utama biochar adalah sebagai pembenah tanah yang mampu memperbaiki produktifitas lahan pertanian, emisi gas rumah kaca dan mencegah pencemaran lingkungan. Biochar dapat bertahan lama ditanah (>400 tahun) karena sulit terdekomposisi. Nurida dkk, (2009) menyatakan bahwa aplikasi biochar pada 
lahan pertanian dapat menigkatkan kualitas tanah karena kemampuannya dalam menyimpan atau menahan air dan hara, meningkatkan pH dan KTK.

Selain itu, biochar mampu bertahan lama ditanah (>400 tahun) karena sulit terdekomposisi. pengaplikasian biochar ke tanah mempengaruhi pertumbuhan tanaman, untuk meningkatkan kapasitas tukar kation, penambahan unsur hara. Unsur hara $\mathrm{N}$ yang terdapat pada biochar kelapa sawit akan tersedia bagi pertumbuhan tanaman yang diperlukan untuk pertumbuhan batang, tinggi dan, jumlah daun kelapa sawit sertamedia tumbuh juga mempengaruhi pertumbuhan tanaman. Febrianti (2012) menyatakan Penambahan arang ke dalam tanah dapat meningkatkan pertumbuhan tanaman, daya simpan dan ketersediaan hara yang lebih tinggi. Pertumbuhan tinggi tanaman dipengaruhi oleh unsur hara nitrogen yang tersedia di dalam tanah. Nitrogen yang terdapat dalam arang batang kelapa sawit tersedia perlahanlahan bagi pertumbuhan tanaman yang diperlukan untuk pembentukan atau pertumbuhan bagian-bagian vegetatif tanaman. Media tumbuh memiliki peran yang besar terhadap pertumbuhan tanaman.

\section{Simpulan}

Pemberian biochar belum memberi pengaruh nyata terhadap parameter tinggi tanaman, diameter batang, dan jumlah pelepah bibit kelapa sawit di Main Nursery salama 3 bulan dalam pengamatan (12 minggu).

\section{Referensi}

Armini., Gulat, M.E.M., Wardati. 2013. Pertumbuhan Bibit Sawit (Elaeis guenensis Jacq.) Di Main Nursery Pada Beberapa Medium Pertumbuhan Pupuk Organik. Fakultas Pertanian. Universitas Riau. Pekanbaru.

Direktorat Jenderal Perkebunan. 2013. Luas Areal dan Produksi Kelapa Sawit Menurut Provinsi di Indonesia Tahun 2008-2012. http://www.pertanian.go.id (29 Januari 2014).

Febrianti. 2012. Peranan Arang Batang Kelapa Sawit Dalam Peningkatan Produksi Tanaman Jagung. Institute Pertanian Bogor. Bogor.

Haryanti, A., Norsamsi., Putri, S.F.S., Novy, P.P. 2014. Studi Pemanfaatan Limbah Padat Kelapa Sawit. Teknik Kimia. Universitas Mulawarman. Samarinda.

Lehnmann, J. 2009. Biochar for Environmental Management. Pp:1-12.

Nurida, N.L., A. Dariah dan A. Rachman. 2009. Kualitas limbah pertanian sebagai bahan baku pembenah berupa biochar untuk rehabilitasi lahan. Prosiding Seminar Nasional dan dialog Sumberdaya Lahan Pertanian. Hal 209-215.

Sujana, I,P dan I Nyoman, L,S,P. 2015. Pengolahan Lahan Ultisol Dengan Pemberian Pembenahan Organik Biochar Menuju Pertanian Berkelanjutan. Fakultas Pertanian. Universitas Mahasaraswati Denpasar. Denpasar.

Sukartono dan W.H. Utomo. 2010. Peranan Biochar Sebagai Pembenah Tanah Pada Pertanamn Jagung Di Tanah Lempung Berpasir (Sandy Loam) Semiarid Tropis Lombok Utara. Pusat penelitian Dan Pengembangan Lahan Kering Universitas Mataram. Mataram. 